\title{
Multidisciplinary Approach for Rehabilitation of Young Adult with Amelogenisis I mperfecta
}

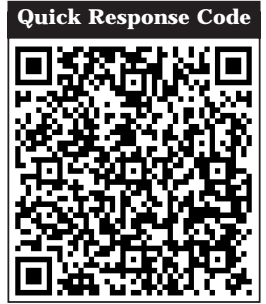

doi: $10.5866 / 2014.631633$

1Postgraduate Student

2,3\&4Professor

Department of Prosthodontics,

Kamineni Institute of Dental Sciences, India

\section{Article Info:}

Article Info:

Received: April 11, 2014

Review Completed: May 12, 2014

Accepted: J une 10, 2014

Available Online: October, 2014 (www.nacd.in)

(C) NAD, 2014 - All rights reserved

\section{Email for correspondence:}

sujana.jasthi@gmail.com

\section{INTRODUCTION}

Amelogenesis imperfecta is a group of developmental conditions, genetic in origin, that affect the structure and clinical appearance of enamel.1, 2 Different inheritance patterns, such as autosomal dominant, autosomal recessive, and sexlinked, as well as sporadic cases have been reported. The incidence of amelogenesis imperfecta has been reported to vary between approximately 1:700 and $1: 16,000$, depending on the population studied and the diagnostic criteria used. ${ }^{3-6}$ Although amelogenesis imperfect has been categorized into four broad groups primarily based on phenotypehypoplastic, hypocalcified, hypomaturation, and hypomaturation-hypoplastic at least 15 subtypes of amel ogenesis imperfecta exist when phenotype and mode of inheritance are considered. ${ }^{2,3,7}$ According to
Sujana J asthi ${ }^{1}$, Taruna $\mathrm{M}^{2}$, Sudhir $\mathrm{N}^{3}$, Ramu Reddy ${ }^{4}$

Amelogenesis imperfecta is a hereditary disorder that causes defective enamel development in the primary and permanent teeth. Significant tooth structure damage often results in various pulpal symptoms, occlusal disharmony, impaired function, and esthetic disfigurement. These problems pose great challenges to the clinician when rehabilitating patients with amelogenesis imperfecta.Clinical treatment is important to address the esthetic appearance of affected teeth, reduce dentinal sensitivity, preserve tooth structure, and optimize masticatory function. This case report describes a multidisciplinary approach for the oral rehabilitation of a young adult patient diagnosed with hypoplastic amel ogenesis imperfecta. The specific objectives of this treatment were to eliminate tooth sensitivity while enhancing esthetics and restoring masticatory function.

Key words: Enamel hypoplasia, Precision attachment, Full mouth rehabilitation, Fixed removable prosthesis.

the literature, amelogenesis imperfecta patients, regardless of subtype, have similar oral complications: abnormal formation of the enamel, teeth with abnormal colour: yellow, brown or grey, higher risk for dental caries, teeth sensitivity, poor dental esthetics, and decreased occlusal vertical dimension. ${ }^{8,9}$ Other dental anomalies associated with amelogenesis imperfecta include, multiple impacted teeth, congenitally missing teeth, open occlusal relationship, and taurodontism. ${ }^{3,10,11}$ The present case report outlines an interdisciplinary approach involving periodontics, endodontics and prosthodontics in the management of patient with amelogenesis imperfecta.

\section{CASE REPORT:}

A 18 year old female patient have reported to the department of prosthetic dentistry with the chief

\section{Indian Journal of Dental AdVAncements}

Journal homepage: www. nacd. in 
complaint of missing posterior teeth in both maxilla and mandible and wants replacement of her teeth. On clinical examination she complained of sensitivity of her teeth along with poor masticatory efficiency. She is dissatisfied with her size, shape and shade of her teeth. History revealed that her primary dentition were erupted with yellowish discoloration and were soon exfoliated. She gave a familial history of her grandfather having the same problem. The patient's medical history revealed no systemic abnormalities. On intraoral examination patient had permanent teeth with loss of enamel, yellowish discoloration and severe attrition leading to loss of vertical height of the face (Figure 1 and 2).

There are missing teeth in relation to $14,15,16,17,25,26,27,34,35,44,45,46$. There was deep anterior bite with no occlusion in relation to posterior teeth. Grade III mobility is present in relation to $26,36,37,47$ and impacted tooth in relation to 48 . The patient's oral hygiene was poor and generalized gingivitis was noted. On radiographic examination there was severe bone loss in relation to edentulous area for both maxilla and mandible (Figure 3). On the basis of clinical and radiographic findings patient is diagnosed of having Type I hypoplastic amelogenesis imperfecta

Treatment options available for the patient are Maxillary and mandibular cast partial denture, Telescopic overdenture replacing maxillary posteriors, Maxillary and mandibular bilateral precision attachment retained prosthesis and Implant supported fixed prosthesis. Among the various treatment options bilateral precision attachment retained fixed removable prosthesis is planned for the patient with cast partial denture and telescopic copings in relation to retained posterior teeth. I mplant supported fixed prosthesis is not planned for the patient as there was severe bone loss in relation to abutment teeth and edentulous area. Treatment planning is mainly divided into two phases.

1. Preprosthetic phase

2. Prosthetic phase

\section{Preprosthetic phase includes}

1. Extraction of teeth in relation to $26,36,37,48$.

2. Oral prophylaxis.

3. Endodontic treatment is done in relation to $12,13,22,23,24,31,32,33,41,42,43$ (Figure 4).

4. Crown lengthening was done in relation to 31 , $32,33,41,42,43$.

\section{Prosthetic phase includes}

1. Diagnosticimpressions were madeand mounted on semi adjustable articulator using a face bow.
2. Patient was given an interim removable partial denture by increasing the vertical dimension to about $3 \mathrm{~mm}$ in order to assess the lost vertical height. Patient is recalled after two weeks to verify the increased vertical height. Patient got adjusted to the given vertical height without any symptoms. Diagnostic wax up is done on the mounted casts.

3. The attachment system was selected on the basis of available space. Tooth preparation was done on $11,12,13,14,18,21,22,23,28,31,32$, 33, 38, 41, 42, 43.

4. Impressions were made and casts poured with die stone. Wax pattern is fabricated on all prepared teeth.

5. The male component was attached to the axial surfaces of the abutment bilaterally on both arches in relation to $14,23,33,43$ using dental surveyor. I nvesting, casting and burnout of the wax pattern was done.

6. Metal try in of the copings was done to evaluate the fit of the casting. Ceramiclayering was done on the framework and tried.

7. The fabricated metal ceramic crowns were provisionally cemented with the attached male component and pick up impression is made using putty and light body to fabricate final prosthesis (Figure 5 and 6)

8. Removable framework is fabricated from the casts and female component is incorporated within the tissue surface of the prosthesis and tried in patients' mouth.

9. Occlusal rims were fabricated on maxillary and mandibular frameworks and maxillomandibular relations are recorded. Teeth arrangement and try in was done followed by acrylization.

10. The fixed partial denture was cemented with glass ionomer cement and the removable partial denture with bilateral precision attachment is inserted (Figure 7, 8). Post insertion checkup was done for 1 to 2 week interval.

\section{DISCUSSION:}

There are many alternative restorative procedures for amelogenesis imperfecta. Each method has its own limitations and it should be critically reviewed prior to deciding a treatment plan. The treatment for patients with amelogenesis imperfecta is related to many factors including the age of patients, the socio-economic status, the type and severity of the disorder, its intra oral manifestation and aesthetic and functional demands. ${ }^{12}$ 


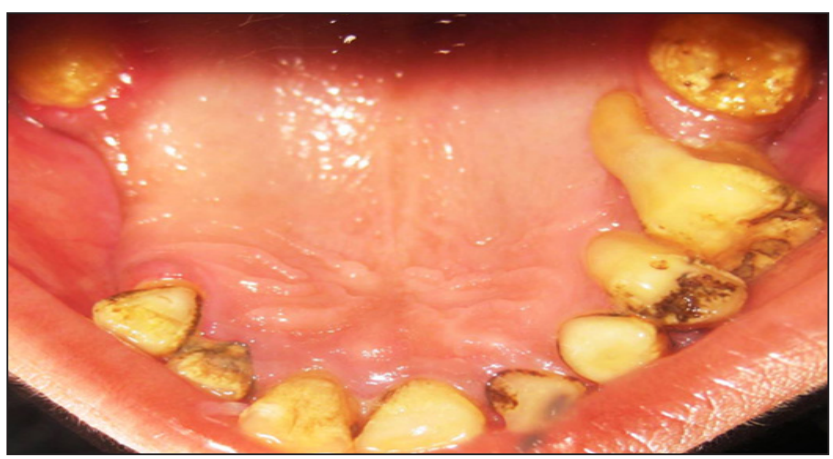

Figure 1: Maxillary preoperative intraoral view showing yellowish discoloration of teeth.

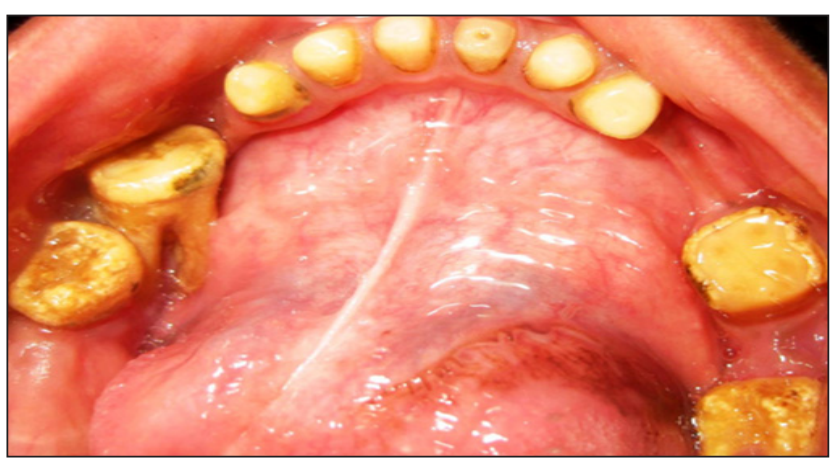

Figure 2: Mandibular preoperative intraoral view showing severe attrition of teeth in relation to lower anteriors.

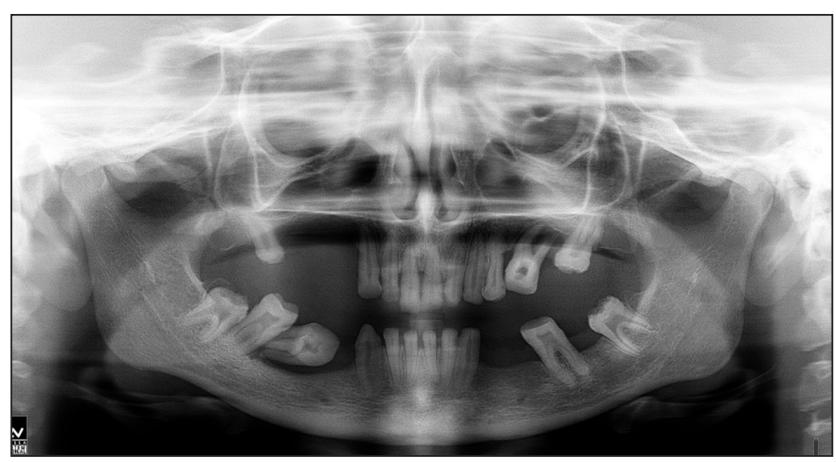

Figure 3: Preoperative radiograph showing generalized bone loss and impacted tooth in relation to 48.

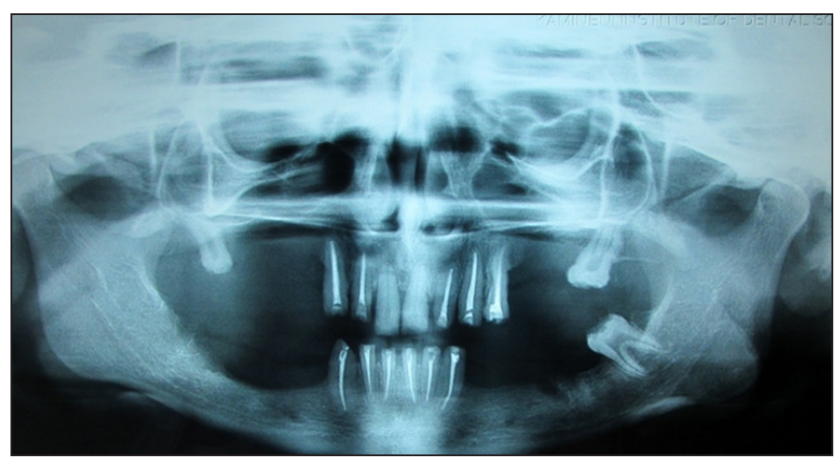

Figure 4: Post endodontic radiograph showing endodontic treatment done in relation to $12,13,22,23,24,31,32,33,41,42,43$.

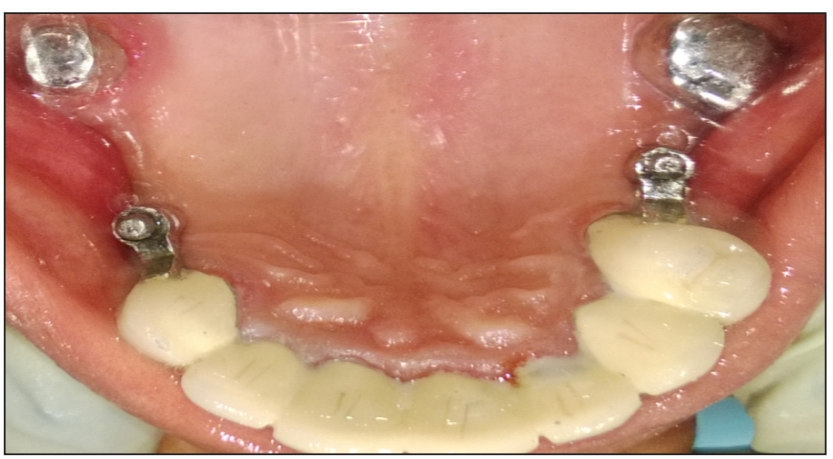

Figure 5: Maxillary metal ceramic crowns with attached male component and telescopic retainers.

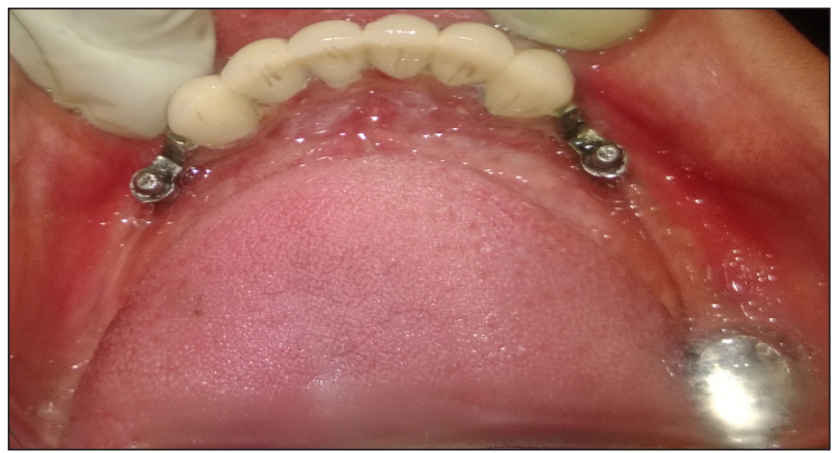

Figure 6: Mandibular metal ceramic crowns with attached male component and telescopic retainer.

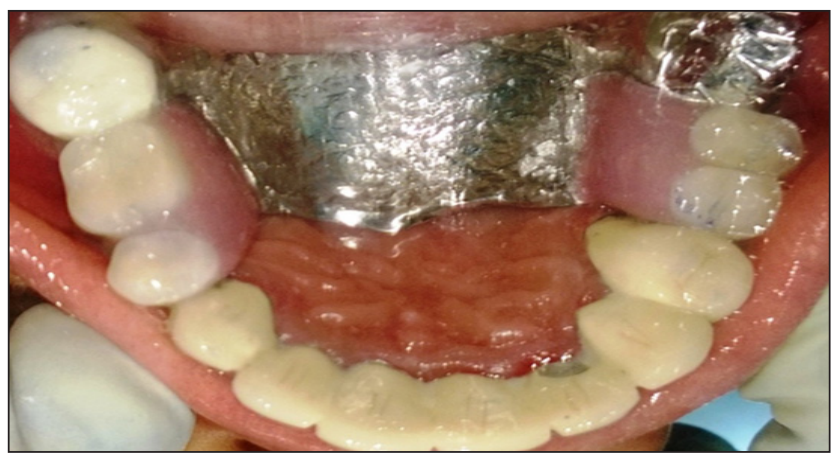

Figure 7: Maxillary post operative intraoral view showing palatal strap along with fixed removable prosthesis.

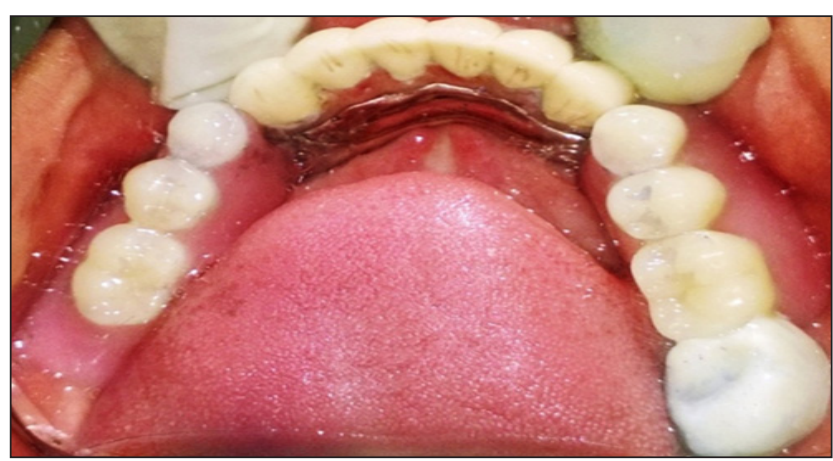

Figure 8: Mandibular postoperative intraoral view showing lingual palatal plate along with fixed removable prosthesis. 
The three factors which play a major role in occlusion are vertical dimension, anterior guidance and posterior inclines. In the present treatment approach there was need to raise the vertical dimension by $3 \mathrm{~mm}$. While most patients could adapt to the raised vertical dimension, it has been reported that some patients exhibited headache, muscle fatigue, sore teeth, and parafunction. ${ }^{13,14}$ It is al ways helpful to evaluate a patient's adaptability by provision of a diagnostic interim removable partial denture for a trial period. This approach is useful in assessing the patient's adaptability to the new raised vertical dimension and acceptance of the anticipated appearance before making definite preparations on the patient's teeth. Such an approach is more convenient for the patient's maintenance and allows easy subsequent replacement with definitive restorations. In the present treatment plan by providing an interim removable partial dentureadaptation of the patient, to the raised vertical dimension and providing adequate crown height for the definitive restorations is assessed. The patient could adapt to the raised vertical dimension without reporting any of the above said symptoms. The crown height of the anterior teeth needed to be lengthened to enhance esthetics and retention. As there was sufficient amount of interocclusal clearance and adequate abutment height, the attachment retained fixed removable prosthesis is planned for the patient.

The use of attachment aid in more apical transmission of forces and reducing stress transfer to the abutments (stress breaking function) and direct the forces to the residual ridge acting as stress redirectors. ${ }^{15}$ Multiple abutments were splinted anterior to the edentulous span to aid in better distribution of stresses. Telescopic retainers are indicated in relation to posterior teeth as they cause reduction of lateral stress on abutment teeth by allowing for self-releasing or stress conversion. ${ }^{15}$ They provide a biomechanical linkage between abutment teeth and edentulous areas.I $n$ this patient after vertical dimension is established, anterior guidance is determined by proper overbite and overjet relationship and accordingly the occlusion of posterior teeth is established. Thus a bilateral balanced scheme of occlusion is established for the patients. In a bilateral balanced occlusion maximum numbers of teeth are in contact in maximum intercuspation and in all excursive positions. Thus it helps in maintaining denture stability; and the contacts on the non-working side prevent the denture form being dislodged from oblique forces.

The cast partial denture is a fixed removable type, maintenance of the oral hygiene is relatively easy. After prosthetic rehabilitation, both facial appearance and occlusion were improved .By the end of treatment plan the patient reported great satisfaction and reported better self confidence.

\section{CONCLUSION:}

Achieving optimum esthetic improvement and functional rehabilitation in $\mathrm{Al}$ patients can be challenging. Poor esthetics, worn dentition, and interocclusal space problems complicate the treatment course of Al patients. This case report described the oral rehabilitation of young adult with bilateral precision attachment retained fixed removable prosthesis in order to eliminate tooth sensitivity, improve esthetics, and restore function.

\section{REFERENCES:}

1. Rajpar MH, Harley K, Laing C, Davies RM, Dixon MJ . Mutation of the gene encoding the enamel specific protein, enamelin, causes autosomal-dominant amelogenesis imperfecta. Hum Mol Genet 2001; 10:1673-1677.

2. Aldred MJ, Savarirayan R, Crawford PJ . Amelogenesis imperfecta: A classification and catalogue for the 21st century. Oral Dis 2003; 9:19-23.

3. Witkop CJ, Rao SR. Inherited defects in tooth structure. Birth Defects Orig Artic Ser 1971; 7:153-184.

4. Backman B, Holm AK. Amelogenesis imperfecta: prevalence and incidence in a northern Swedish county. Community Dent Oral Epidemiol 1986; 14:43-47.

5. Sundell S, Koch G. Hereditary amelogenesis imperfecta. Epidemiology and clinical classification in a Swedish child population. Swed Dent J 1985; 9:157-160.

6. Witkop CJ. Hereditary defects in enamel and dentin. Acta Genet Stat Med 1957; 7:236-239.

7. Weinmann J P, Svoboda J F, Woods RW. Hereditary disturbances of enamel formation and calcification. J Am Dent Assoc 1945; 32:397-418.

8. Seow WK. Clinical diagnosis and management strategies of amelogenesis imperfecta variants. Pediatr Dent 1993; 15:384-393

9. Coffield KD, Phillips C, Brady M, Roberts MW, Strauss RP, Wright J T. The psychosocial impact of developmental dental defects in people with hereditary amelogenesis imperfecta. J Am Dent Assoc 2005; 136:620-630.

10. Aldred MJ, Crawford PJ M. Variable expression in amelogenesis imperfecta with taurodontism. J Oral Pathol Med 1988; 17: 327-333.

11. Ayers KMS, Drummond BK, Harding WJ , Salis SG, Liston PN. Amelogenesis imperfecta-multidisciplinary management from eruption to adulthood. Review and case report. N Z Dent J 2004; 100:101-104.

12. Laxman rao, Veena J ain. Oral rehabilitation of a case of amel ogenesis imperfecta. Annals and Essences of dentistry 2011; 3(1):50-55.

13. Dawson PE. Evaluation, Diagnosis and Treatment of Occlusal Problems, ed 2. Toronto: Mosby, 1989.

14. Silverman MM. Vertical dimension must not be increased. J Prosthet Dent 1952; 2:188-1897.

15. Breitman et al. Telescopic retainers: An old or new solution? A second chance to have normal dental function. J Prostho 2012; 21:79-83. 